\title{
Proposal for a name change for Education for Information
}

Dear subscribers and readers,

Last autumn, I wrote to inform you of exciting new developments and the new directions in which I was taking the journal, in particular, of the expanded scope of the journal and the line up of exciting issues forthcoming. A lot has happened since my last letter to you. The four issues of 2018 have been delivered to you by the end of 2018, comprising three special issues: (i) Non textual approaches to teaching in the information field guest-edited by Kiersten Latham (Kent State University, OH, USA) and Tim Gorichanaz (Drexel University, PA, USA); (ii) Information, Knowledge, Autonomous Action and Big Data guest-edited by Daniel Martinez-Avila (Sao Paolo State University, Brazil) and (iii) Evaluating online Health information sources using a mixed method approach guest-edited by Vera Granikov and Pierre Pluye (University of McGill, QC, Canada).

In the winter of 2018, my editorial board and I embarked on a month-long discussion on the merits of changing the name of the journal in order to align it with its expanded scope. The current title is still limiting in that it is the first information potential authors come across and it also creates ambiguity by attracting submissions on education and pedagogy in general.

We wish to signal to potential authors that the journal is open for "business" and that it welcomes publications on all topics of interest to the information fields (iFields). These include but are not limited to education, pedagogy and learning in the iFields; information seeking and use; information policy and ethics; information retrieval; digital humanities; documentation theory and practice; data science; gender studies in the iFields, etc. The journal welcomes broad methodological approaches to these topics, including empirical quantitative or qualitative studies as well as reflexive, hermeneutical and other conceptual approaches. The journal also welcomes historical and foundational research in the iFields, including works that bridge the gap between the iFields and other fields, such as Science and Technology Studies or the Philosophy of Technology, Philosophy, Media Studies.

This month-long discussion culminated in the suggestion of "Interdisciplinary Journal of Information Studies" as a new name for the journal.

The publisher is prudently considering this new name by first appending it as a subtitle to the current name, hence the longer title you are receiving in this first issue of 2019.

We would love to hear your thoughts about the suggested name change before a 
final decision is made. Thank you for your fidelity. We look forward to bringing you more thought provoking contents!

Yours sincerely, Fidelia Ibekwe-SanJuan

Editor-in-Chief 